\section{0 psicólogo escolar em políticas públicas no Piauí: mapeamento e demandas}

\author{
Bruna Saraiva Candeira \\ Leilanir de Sousa Carvalho \\ Fauston Negreiros
}

\section{RESUMO}

A presente pesquisa versa acerca da atuação do psicólogo escolar nas políticas públicas no contexto histórico-cultural piauiense. Essas norteiam a relação entre Estado e sociedade, tendo em vista as demandas sociais que emergem e que, assim, requerem intervenções a fim de manter o estado de sociabilidade e de garantia de direitos, como o direito à educação. Nessa perspectiva, a pesquisa aqui descrita teve como objetivo identificar psicólogos inseridos nas políticas públicas educacionais no estado do Piauí e caracterizar sua atuação profissional. Utilizou-se a abordagem qualitativa de pesquisa, e foram entrevistados 42 psicólogos que atuam em políticas públicas educacionais no estado do Piauí. Foram utilizados os instrumentos: formulário de identificação de políticas públicas; entrevista semiestruturada; e questionário sociodemográfico. Foram analisados pelo procedimento de análise de conteúdo. Identificaram-se, sobretudo, os eixos de políticas nos quais estão inseridos, assim como as demandas educacionais e limitações recorrentes na referida realidade. Espera-se que o levantamento aqui realizado possa ser utilizado a fim de delinear práticas futuras em políticas públicas educacionais acerca das demandas levantadas, sobretudo com relação àquelas que são recorrentes, mas que não vêm sendo contempladas nas práticas e nos modos de atuação.

Palavras-chave: psicólogo escolar; políticas públicas de educação; Piauí.

\section{ABSTRACT}

\section{The school psychologist in public policies in Piaui: Mapping and demands}

The present research deals with the performance of the school psychologist in public policies in the historical-cultural context of Piauí. These guide the relationship between the State and society in view of the emerging social demands and thus require interventions in order to maintain the state of sociability and guarantee of rights, as well as education. From this perspective, the research described here aimed to identify psychologists inserted in public educational policies in the state of Piauí and to characterize their professional performance. The qualitative research approach was used, and 42 psychologists were interviewed which work in educational public policies in the state of Piauí. The interviews, in which three instruments of data collection were used: form of identification of public policies; semi structured interview; and sociodemographic questionnaire. They were analyzed by the content analysis procedure. It was identified, above all, the policy axes in which they are inserted, as well as the educational demands and recurrent limitations in the aforementioned reality. It is hoped that the survey carried out here may be used in order to delineate future practices in public educational policies about the demands raised, especially in relation to those that are recurrent but that are not being contemplated in the practices and modes of action.

Keywords: school psychologist; public education policies; Piauí.

As Políticas Públicas são princípios norteadores de ação do poder público; procedimentos para as relações entre poder público e sociedade, mediações entre atores da sociedade e

\section{Sobre os autores}

B. S. C.

http://orcid.org/ 0000-0003-

3123-438X

Universidade Federal do Piauí Parnaíba, PI

brusaraivac@gmail.com

L. S. C.

http://orcid.org/ 0000-00026350-560X

Universidade Federal do Piauí Parnaíba, PI

leilanircarvalho@ymail.com

F. N.

http://orcid.org/ 0000-0003-

2046-8463

Universidade Federal do Piauí Parnaíba, PI

faustonnegreiros@ufpi.edu.br

\section{Direitos Autorais}

Este é um artigo de acesso aberto e pode ser reproduzido livremente, distribuído, transmitido ou modificado, por qualquer pessoa desde que usado sem fins comerciais. 0 trabalho é disponibilizado sob a licença Creative Commons CC-BY-NC.

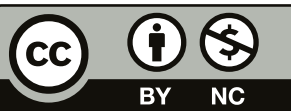




\section{M." INTERACÃO EM PSICOLOGIA}

do Estado. São, assim, políticas explicitadas e sistematizadas que orientam ações que normalmente envolvem aplicações de recursos públicos, formuladas em resposta a determinados problemas sociais, de modo a funcionarem como meios de regulação das relações sociais, ou seja, emergem a partir de demandas sociais (Dimenstein, 2011; Negreiros et al., 2018).

No transcorrer da história social, política e econômica brasileira, a instalação e a execução de políticas públicas ocorreram de formas diversas, a depender, sobretudo, do período político do país. Após o período de Ditadura Militar, fase de regime autoritário baseado na restrição de direitos civis e políticos, acompanhado por medidas voltadas à legitimação do autoritarismo, os anos 1980 foram marcados pela democratização do país e pela crise do nacional-desenvolvimentismo (Farah, 2016).

De acordo com Farah (2016) e com Zibetti et al. (2018) o regime de políticas públicas sofreu uma alteração com a criação, a partir da Constituição de 1988, de mecanismos de participação da sociedade civil na formulação, implementação e controle das políticas. Mas o contexto de crise fiscal e de endividamento externo conduziu também à adoção pelo governo de políticas de ajuste.

O termo "público", associado à política, não é uma referência exclusiva ao Estado, mas sim à noção de coisa pública (de todos). Embora as políticas públicas sejam reguladas e frequentemente providas pelo Estado, é importante ressaltar que elas também englobam preferências e escolhas privadas, podendo e devendo ser controladas pelos cidadãos (Cruz \& Guareschi, 2017).

Assim, no Brasil (com a Constituição de 1988), mudanças ocorreram na gestão pública e nas políticas públicas sob o efeito de dois movimentos: a democratização, orientada pela perspectiva de direitos, e a busca da eficiência na utilização de recursos públicos. Nesse contexto, as políticas públicas passaram a ocupar um lugar central na agenda governamental (Farah, 2016).

Pode-se considerar que, em períodos de crise financeira generalizada, torna-se comum a utilização de medidas políticas e econômicas internacionalizadas e oriundas dos grandes centros urbanos. Essas medidas, em geral, são tomadas e gerenciadas por organismos multilaterais de financiamento, em acordo, através do Estado, com os governos que os representam (Fontes, 2010; Harvey, 2010/201 1; Zibetti et al., 2018).

Assim, a aplicação de políticas públicas são estratégias decorrentes das tentativas de reconfiguração global da sociabilidade, dentro do modo de produção estabelecido. Por esse entendimento, a área de políticas públicas para a Educação está presente nessas medidas (Zibetti et al., 2018).

A partir da década de 1990, com a redemocratização do Estado brasileiro, conseguiu-se que o campo da educação ti- vesse autonomia para planejar e implementar políticas públicas e, nesse período, a psicologia na sua relação com a educação começa a ter uma importante função. Essa interseção entre psicologia e educação apontou para a importância da criação de políticas, de maneira a buscar garantir que os indivíduos possam ser sujeitos transformadores na sociedade, através de conhecimentos construídos e apropriados (Leonardo et al., 2018; Souza \& Cunha, 2010).

A matriz teórica da Psicologia Histórico-Cultural, liderada por Vygotsky, entende o processo educativo como principal mediador entre a história dos instrumentos e signos desenvolvidos e aperfeiçoados pelo homem em sua totalidade histórico-social. De acordo com Vygotsky (1999) a importância da Psicologia se dá no ato de objetivar e explicar o modo como se dá a formação do sujeito e qual o papel da cultura como resultado dos trabalhos concretos do conjunto societário.

A respeito da atuação da Psicologia no âmbito das Políticas Públicas Educacionais, Antunes (2003) e Zibetti et al. (2018) destacam que o desenvolvimento da Psicologia Escolar e Educacional no Brasil, sobretudo nos anos 1930, esteve atrelado às demandas de um país em crescente processo de urbanização e industrialização, que apostava na Educação para a concretização do seu desenvolvimento. Dessa forma, a preocupação com a eficiência no ensino teve como aliado os conhecimentos sobre os fenômenos psicológicos, especialmente aqueles capazes de minimizar as diferenças, prevenir os erros e controlar a conduta das pessoas.

Nos anos 1970, é possível constatar que o foco da atenção esteve no aluno desviante da norma, objetivando adaptá-lo aos padrões da sociedade. Assim, inicialmente, a Psicologia ofereceu explicações para o fracasso escolar pautadas na teoria da carência cultural e intervenções intensamente marcadas por uma prática individualizada, psicodiagnóstica e psicoterapêutica (Collares \& Moysés, 2015; Patto, 2000).

Com a finalidade de modificar essa perspectiva, uma atuação do psicólogo escolar pensada numa perspectiva crítica precisaria levar em conta: os modos de produção da queixa escolar; a construção de referenciais interpretativos que tenham como princípio a construção de uma história não documentada, composta por diferentes versões (criança, pais, professores, psicólogo) a respeito da criança e de sua relação com a escolarização e a constituição de uma atuação profissional com finalidade emancipatória (Campos et al., 2018; Souza \& Checchia, 2003).

Importante considerar que as discussões sobre políticas públicas em educação são questões recentes no campo da Psicologia Escolar e Educacional (emergiram nos últimos 30 anos), na medida em que essa passou a ser questionada em suas finalidades. A tese de doutorado de Maria Helena Souza Patto - defendida em 1981 e publicada em 1984 na obra Psi- 


\section{MLE INTERACÃO EM PSICOLOGIA}

cologia e Ideologia: uma introdução crítica à Psicologia Escolar (Patto, 1984) - introduziu as discussões sobre o tema no Brasil (Leonardo et al., 2018)

Nessa perspectiva, Gomes e Souza (2015) destacam que os desafios da Educação no Brasil contemporâneo exigem que o psicólogo se envolva também nas questões políticas e sociais, e não apenas nas questões estritamente psicológicas. As políticas educacionais estão em constante relação e interferência na vida diária escolar e imprimem decisões na constituição do processo de escolarização, afetando diretamente as concepções que circulam entre os educadores a respeito do processo de ensino-aprendizagem, assim como a representação que alunos e pais têm da escola.

De acordo com Damasceno e Negreiros (2018), é primordial, na prática do profissional da educação - dentre estes, o Psicólogo Escolar Educacional (PEE) - conhecer as singularidades dos alunos e melhor relacioná-las com sua ação, para em seguida mapear as ações e as tentativas de mudança que podem ser feitas no intuito de não só favorecer a aprendizagem dos mesmos, mas também de não deixá-los desanimar diante dos desafios encontrados.

Entretanto, ao elencar os profissionais da Educação, o Título VI da Lei de Diretrizes e Bases da Educação Nacional (Lei n 9.394, 1996) não faz referências ao psicólogo e, em tese, este não poderia estar inserido no cotidiano escolar. Com isso, a falta de uma legislação que garanta a contratação desse profissional para trabalhar especificamente na Educação acaba por ocasionar situações como: desvio de função, realocação do profissional em outras secretarias ou serviços e descontinuidade do trabalho. Portanto, é nesse cenário que é contratado o psicólogo para atuar na Educação - não há uma política de atuação claramente definida (Gomes \& Souza, 2015).

Desse modo, a respeito da inter-relação entre Estado, políticas públicas, educação e desenvolvimento humano, observa-se a necessidade de considerações específicas por parte do saber da Psicologia, uma vez que é uma área de estudo e de ação que tem como característica - sobretudo na vertente da Psicologia Histórico-Cultural - intermediar as fronteiras nas relações entre esses elementos (Barroco \& Silva, 2015).

No que se refere à Psicologia no Piauí, de acordo com Silva e Yamamoto (2013), o estado possui uma inserção recente da Psicologia, se comparado aos demais estados brasileiros, tendo os primeiros cursos sido implantados apenas no final da década de 1990 - acompanhando a expansão da educação superior no Brasil após a Lei de Diretrizes e Bases da Educação Nacional (Lei nº 9.394, 1996).

Em um estudo realizado no Piauí por Macedo e Dimenstein (2011), 47,28\% dos profissionais inscritos no Conselho Regional de Psicologia estavam atuando nos aparelhos do Estado, por meio das políticas que compõem a seguridade social brasileira, no referente ano. Diante dessa realidade de envolvimento nas políticas públicas, torna-se importante apreender de que forma atualmente se dá o delineamento dos psicólogos que atuam nas políticas públicas educacionais.

Assim, mediante a realidade contemporânea e a relevância do serviço do profissional psicólogo no campo das políticas públicas de educação, a presente pesquisa tem como objetivo identificar psicólogos inseridos nelas no contexto histórico-cultural piauiense e caracterizar sua atuação profissional na rede pública de ensino.

\section{MÉTODO}

\section{TIPO DE ESTUDO}

0 presente estudo categoriza-se como de abordagem qualitativa. Conforme Minayo (2004), essa é uma metodologia que incorpora a questão do significado e da intencionalidade como inerente aos atos, às relações, e às estruturas sociais, sendo essas últimas tomadas tanto no seu advento quanto na sua transformação como construções humanas significativas. E, em conformidade com os objetivos da pesquisa, o estudo se classifica como do tipo descritivo, pois pretende descrever os fatos e fenômenos de uma determinada realidade (Gil, 2010).

\section{PARTICIPANTES}

A pesquisa contou com a participação de 42 profissionais psicólogos atuantes na rede pública de educação do estado do Piauí. Desses, a maioria é do sexo feminino (88,1\%), e a idade varia de 24 a 57 anos (Média= 35,59; DP=9,039). Quanto à cidade em que estão atuando, a maioria $(42,86 \%)$ está na capital do estado, Teresina, seguidos por $9,52 \%$ que atuam em Parnaíba, a segunda cidade mais populosa do estado, e por $4,76 \%$ em Paulistana. Os outros $42,86 \%$ são compostos por psicólogos que estão, cada um, em uma das respectivas cidades: Barras, Cocal dos Alves, União, Floriano, Uruçuí, Picos, Piripiri, Regeneração, São Raimundo Nonato, Fronteira, Altos, Valença, Caldeirão Grande, Campo Maior, Oeiras, Bom Jesus, São João e Corrente. Assim, o Piauí possui 224 municípios, e a presente pesquisa contou com a participação de psicólogos de 21 municípios.

Quanto ao local em que atuam, duas psicólogas atuam na Secretaria Municipal de Educação (Semec) de Teresina, e 40 psicólogos atuam na Secretaria Estadual de Educação (Seduc) do Piauí. Dentre esses últimos, duas são lotadas no Conselho Estadual de Educação, sendo que uma dessas é a Diretora do Programa Nacional de Acesso a Ensino Técnico e Emprego (Pronatec) no Piauí. 
Ainda na Seduc, há também uma psicóloga que atua na Coordenação do Pronatec e outra que atua na Coordenação do Núcleo de Atenção Psicossocial (Nuapsi). 26 dos psicólogos atuam nas Gerências Regionais de Educação (GREs) do estado e outras oito psicólogas que atuam pela Seduc estão lotadas como psicólogas sem discriminação específica de campo de atuação. Dentre os citados que atuam na Seduc, ressalta-se que ao todo 22 atuam como psicólogos do Pronatec (incluindo a diretora e a coordenadora do referido programa no estado do Piauí), o que corresponde a $52,38 \%$ dos entrevistados.

\section{INSTRUMENTOS}

Como instrumentos de investigação utilizaram-se: um Formulário de Identificação de Políticas Públicas de Atuação do Psicólogo Escolar (composto por onze perguntas abertas direcionadas para melhor compreender como é a atuação do psicólogo nas respectivas políticas públicas em que estão envolvidos), um Roteiro de Entrevista Semiestruturada acerca da Psicologia Escolar na área das Políticas Públicas (composto por dezoito perguntas abertas abrangendo, sobretudo, questões acerca da Psicologia Escolar, dos projetos em que os psicólogos estão envolvidos e de que forma eles percebem que se delineia a atuação do profissional da psicologia nas políticas públicas) e um Questionário Sociodemográfico (com questões sobre sexo, idade, renda, estado civil, local(is) de formação, local(is) de trabalho atual, dentre outras, com a finalidade de delinear um perfil dos psicólogos hoje lotados nas políticas públicas de educação).

Os instrumentos acima citados foram elaborados pelos pesquisadores tendo como base os estudos documentais que compõem o referencial teórico da presente pesquisa.

\section{PROCEDIMENTOS}

Em conformidade com a resolução 510/ 2016, a presente pesquisa primeiramente foi submetida ao Comitê de Ética e Pesquisa em Seres Humanos. Foi aprovada com o número do parecer 2.708.244. Em seguida, foram contatados profissionais da psicologia da Rede Pública de Educação do Piauí através de registros oficiais das Secretarias Municipais e Estadual de Educação.

Durante as entrevistas foram aplicados o Formulário de Identificação de Políticas Públicas de Atuação do Psicólogo Escolar, o Roteiro de Entrevista Semiestruturada acerca da Psicologia Escolar na área das Políticas Públicas e o Questionário Sociodemográfico. As entrevistas que foram realizadas pessoalmente foram gravadas, mediante a permissão do psicólogo entrevistado e duraram em média $1 \mathrm{~h}$ e $15 \mathrm{~min}$.

\section{PROCEDIMENTOS DE ANÁLISE DOS DADOS}

Os dados da presente pesquisa foram analisados através do procedimento de Análise de Conteúdo. De acordo com Bardin (1977/2006), essa é uma das técnicas mais utilizadas em pesquisas empíricas realizadas em diferentes ciências humanas e sociais. Com relação à análise, é enfatizada a análise de ocorrências, com o objetivo de focar a atenção aos relatos dos sujeitos entrevistados e, assim, construir eixos temáticos de análise.

\section{RESULTADOS E DISCUSSÃO}

Uma vez que a presente pesquisa objetiva identificar Políticas Públicas de Educação no contexto histórico-cultural piauiense que possuam psicólogos atuando e, assim, mapear e apreender de que forma está ocorrendo a atuação deles, falar-se-á, inicialmente, acerca de dados referentes à maneira como os psicólogos participantes percebem a Psicologia Escolar, já que essa é área em que os mesmos estão, para depois adentrar no mapeamento da atuação.

De acordo com as respostas à pergunta 1 (0 que você entende por Psicologia Escolar?) do Roteiro de Entrevista Semiestruturada, percebeu-se que as respostas se organizavam em três eixos.

O primeiro, o qual englobou as respostas de $85 \%$, é o de psicólogos que corroboram com o pensamento da Psicologia Escolar Educacional Crítica. Esta se caracteriza pela atuação do psicólogo no contexto de ensino e aprendizagem, com o objetivo de contribuir para aperfeiçoar o processo educativo e social, entendido este como complexo processo de transmissão cultural e de espaço de desenvolvimento (Martinez, 2003). Visa compreender a produção da subjetividade na escola através do olhar direcionado para a complexidade das relações estabelecidas por meio das políticas educacionais e das relações institucionais, pedagógicas, culturais e interpessoais (Barbosa \& Souza, 2012; Checchia \& Souza, 2018).

Dessa forma, essa visão crítica amplia o olhar do psicólogo para os demais atores do espaço escolar, não focando apenas no aluno, partindo de um olhar apenas psicoeducativo, para um também psicossocial. Os seguintes depoimentos de participantes da pesquisa exemplificam a respectiva visão:

[...] voltada para o ensino e aprendizagem, voltada para o desenvolvimento humano, para todos os processos que estão envolvidos nesse ambiente escolar [...] P3.

[...] campo de atuação do psicólogo que deve ser bem abrangente porque você vai trabalhar com todos os aspectos relacionados à educação, dentre gestão, gerenciamento de projetos, orientação, apoio familiar e a crianças 


\section{-4: INTERACÃO EM H. PSICOLOGIA}

e adolescentes, mas também às famílias, aos professores, acompanhamento de programas de políticas públicas como EJA, como Jovem de Futuro [...] P17.

[...] foco da escola como um todo [...] você vai precisar olhar para todas as relações humanas existentes naquele ambiente [...] P31.

Apenas $11 \%$ dos psicólogos tiveram relatos que corroboram o pensamento de uma Psicologia Escolar e Educacional centralizada no aluno, compreendendo este como causa e consequência das situações escolares, sobretudo, as que envolvem seu aprendizado. Dos psicólogos que responderam à questão, 4\% responderam de forma tangente, não respondendo realmente à pergunta. Ver gráfico 1 .

\section{Gráfico 1. Compreensão acerca da Psicologia Escolar}

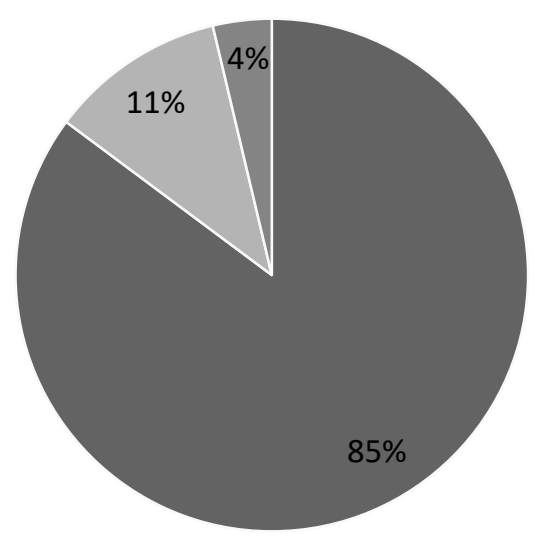

Quanto às limitações observadas para a prática do psicólogo escolar percebidas pelos 42 psicólogos em suas respectivas instituições, a tabela a seguir demonstra a frequência de vezes em que cada uma das seguintes limitações foi relatada.

Dessa forma, é possível perceber que a principal limitação para a atuação do Psicólogo Escolar Educacional (PEE) no Piauí está sendo a limitação de recursos, de estrutura, seguida pela falta de mais profissionais especializados na rede, fator esse que colabora para que haja superlotação (o que inviabiliza o trabalho transdisciplinar e em rede, sobretudo para que o PEE faça encaminhamentos). Leonardo et al. (2018) trazem que a falta de qualidade, das condições materiais e humanas estão relacionadas a situações em que a educação escolar é negligenciada. Isso é ilustrado através das seguintes falas:

[...] déficits no aspecto de suporte técnico/recursal e espaço físico para realizar os atendimentos e escutas individuais quando há a necessidade [...] P13.
[...] o que mais chama a atenção é a estrutura mesmo. A estrutura da escola, o material que eles não têm e aí solicitam muito... De tudo o que você imaginar de material, tanto de estudo como também da parte física [...] P16.

[...] muitas vezes a gente vê que aquele caso tem um perfil que precisa de um encaminhamento pra clínica, e aí a gente não tem pra onde encaminhar, pela superlotação de outros serviços [...] $P 1$.

[...] tem muita demanda, muita demanda... E não é demanda boba não, são demandas mesmo de ideação suicida, situações-limite mesmo que você não tem pra onde encaminhar [...] P2.

\author{
- Visão da Psicologia Escolar e \\ Educacional Crítica \\ - Visão Centralizada no Aluno
}

Resposta Tangente
A falta de reconhecimento pelo trabalho realizado - reconhecimento tanto moral quanto financeiro - assim como o desconhecimento por parte dos outros profissionais da equipe acerca da função do PEE também foram bastante pontuados. Acerca disso, Martinez (2010) assinala que muitas vezes o profissional psicólogo é percebido com receio por parte da equipe pedagógi$\mathrm{ca}$, sendo implicitamente rejeitado, devido às dúvidas do coletivo escolar com relação à sua função e à sua capacidade. Tal fator pode ser ilustrado pelos respectivos extratos das entrevistas:

[...] eu diria que um dos maiores desafios é desconstruir essa imagem que as pessoas têm acerca da psicologia escolar [...] desafio tanto da compreensão das pessoas com relação à psicologia escolar, outros são institucionais e eu também diria nosso mesmo enquanto profissional [...] P1.

[...] fui fazer um trabalho de esclarecimento e humanização sobre o papel do psicólogo e de como o trabalho ia ser feito, então as primeiras perguntas eram "Quer dizer que 
Tabela 1. Limitações para a atuação do Psicólogo Escolar Educacional (PEE)

\begin{tabular}{cc}
\hline LIMITAÇÃo & $\begin{array}{c}\text { Frequência } \mathbf{n}^{\circ} \text { de vezes relatada a } \\
\text { limitação/ } \mathbf{n}^{\circ} \text { de vezes total de } \\
\text { limitações relatadas } \mathbf{x} \text { 100) }\end{array}$ \\
\hline $\begin{array}{cc}\text { Déficits do suporte técnico (materiais, estrutura, recursos) } \\
\text { Falta de mais profissionais especializados/ superlotação da rede }\end{array}$ & $22,45 \%$ \\
Desconhecimento por parte dos outros profissionais da real função do PEE & $20,41 \%$ \\
Falta de reconhecimento & $18,37 \%$ \\
Não estar diretamente nas escolas, mas sim no órgão gestor & $16,33 \%$ \\
Formação falha dos psicólogos com relação à PEE & $8,16 \%$ \\
Resistência por parte dos alunos & $4,08 \%$ \\
Contexto social em que está inserida a escola & $4,08 \%$ \\
\hline TOTAL & $4,08 \%$ \\
\hline
\end{tabular}

Fonte: Pesquisadores.

você vai atender agora na escola?" Então as pessoas ainda têm muito essa ideia de psicólogo ser essencialmente um clínico [...] P17.

[...] em minha opinião, as pessoas poderiam ver esse campo com um olhar mais sensivel, e investir mais nesse profissional [...] P31.

[...] na rede pública, ainda não tem efetivado o cargo de psicólogo escolar, então é mais difícil o trabalho voltado para o aspecto da escola, quando não se tem uma definição [...] P6.

[...] a gente precisa de incentivo para estar ali dentro, a gente precisa de incentivo do governo, dessas pessoas para a gente estar ali dentro intervindo positivamente, porque a gente vê a diferença [...] P34.

Outra questão levantada pelas entrevistas foi acerca das principais demandas educacionais. Essas estão elencadas no gráfico que segue (ver Gráfico 2), o qual demonstra o número de vezes em que cada uma das seguintes demandas foi relatada pelos psicólogos.

As questões de saúde mental e emocional, juntamente à infrequência e evasão escolar e ao comportamento autolesivo, foram as três demandas mais ressaltadas. A recorrência dessas demandas reforça a importância de se olhar não apenas para o aluno, mas também para todo o contexto social no qual ele está inserido, reconhecendo que os indivíduos se constituem e ao mesmo tempo são constituidores dos contextos sociais, dos quais podem emergir demandas relacio- nadas não estritamente ao processo de aprendizagem, mas também, por exemplo, a questões de saúde mental e do contexto sociocultural (Collares \& Moysés, 2015).

Isso corrobora a perspectiva da Psicologia Escolar Educacional Crítica, a qual muda o foco de análise do profissional psicólogo - até então centralizado no indivíduo - para compreender os fenômenos escolares com um olhar ampliado, crítico (Checchia, 2015; Martinez, 2010).

Tradicionalmente, o papel do psicólogo que atua no contexto escolar foi atrelado à atuação diante das dificuldades de aprendizagem (Collares \& Moysés, 2015; Patto, 2000), todavia, os resultados da presente pesquisa demonstram que essa demanda atualmente vem sendo uma das menos recorrentes (no contexto piauiense).

Esse fato é importante, pois também reforça a perspectiva da Psicologia Escolar Educacional Crítica, a qual propõe uma ampliação do olhar das demandas escolares para além dos problemas intrínsecos ao alunado, buscando ampliar a dimensão psicoeducativa, somando a ela a dimensão psicossocial - aliando assim as práticas tradicionais com as práticas emergentes do PEE, aliando a teoria à prática, aliando a Psicologia Educacional à Psicologia Escolar (Checchia \& Souza, 2018; Martinez, 2010; Meira, 2000).

A partir do levantamento de demandas, é possível ampliar também o modo como se delineia a atuação do PEE nas Políticas Públicas Educacionais, mapeando assim em quais eixos eles estão envolvidos. Nessa perspectiva, organizou-se a forma de atuação dos 42 psicólogos nos seis eixos de atuação em políticas públicas elencados pelo Grupo de Trabalho (GT) 


\section{Gráfico 2. Demandas Educacionais}

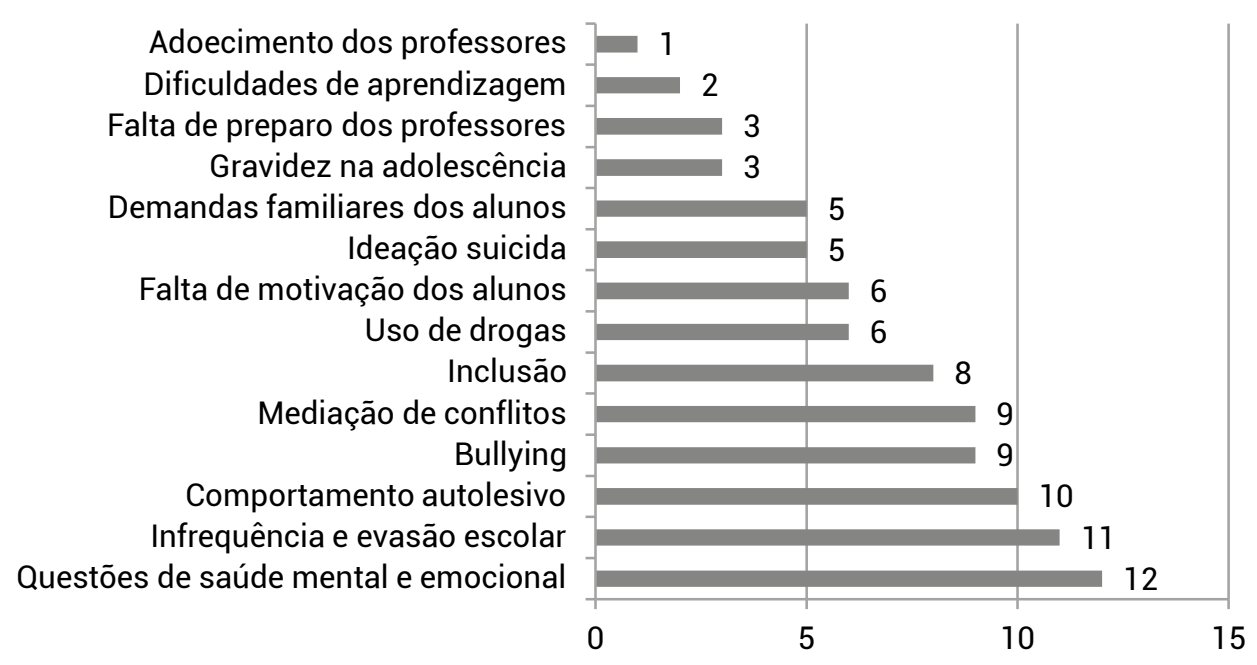

Fonte: Pesquisadores.

Psicologia e Políticas Educacionais da Associação Nacional de Pesquisa e Pós-graduação em Psicologia (Anpepp) no XVI Simpósio de Pesquisa e Intercâmbio Científico, em junho de 2016 na cidade de Maceió, Alagoas.

Os eixos são: 1) Políticas para educação inclusiva; 2) Políticas de formação e atuação do psicólogo escolar; 3) Políticas de melhoria da educação; 4) Políticas de formação de professores; 5) Políticas de atendimento à diversidade; e 6) Políticas intersetoriais (Urt, 2017). Alocou-se os modos de atuação de cada psicólogo nos referidos eixos tendo como base suas respostas nas entrevistas. Ver Gráfico 3.
A partir disso, é possível perceber que o eixo 3 (Políticas de Melhoria na Educação) de atuação em políticas públicas é o que engloba a maior parte dos PEEs que atuam nas Políticas Públicas no Piauí (69,05\%). Essa realidade se coaduna com uma das principais demandas levantadas pelos psicólogos, a de atuar diante da realidade de infrequência e de evasão escolar, a qual se relaciona também com outra demanda levantada, a de questões de saúde mental e emocional.

Dentre as práticas e projetos em Políticas de Melhoria na Educação, as seguintes falas exemplificam algumas:

\section{Gráfico 3. Contagem de Nº de psicólogos por Politica Pública Educacional}

\begin{tabular}{|}
$\begin{array}{r}\text { Eixo 2 e } 3 \\
\text { Eixo 3, 4, } 6 \\
\text { Eixos 1, 2, 3, 4, 5 e } 6\end{array}$ \\
Eixo 1, 3 e 4 \\
Eixo 1 e 3 \\
Eixo 1
\end{tabular}

Fonte: Pesquisadores. 
[...] o Pacto pela Aprendizagem, ele é um programa da Secretaria voltado para que se atinjam as metas do Ideb, uma vez que é feita a avaliação, são estabelecidas metas que se deseja alcançar, então a Secretaria tem esse Pacto pela Aprendizagem, e dentro desse pacto tem o projeto de Clima Escolar [...] P1.

[...] temos o Pronatec, Mediotec, Jovens do Futuro (que estamos vendo se vamos continuar ou não), o EJA, Educação Inclusiva, tem muita coisa. Eles estão tentando fazer com que esses alunos que são públicos difíceis, principalmente do EJA e Pronatec permaneçam dentro dos programas que conseguimos inserir [...] P3.

[...] atendimentos coletivos em reuniões periódicas com famílias; intervenções com equipes docentes através de projetos educacionais voltados a este público; intervenções em sala de aula com alunos no sentido de efetivar os projetos com temáticas transversais previstos no planejamento anual da escola [...] P13.

[...] orientação a pais e crianças que evadiram da escola, com visitas domiciliares e encaminhamento a demais órgãos [...] P12.

É importante ressaltar que esses dados acerca da demanda de evasão e infrequência, assim como do principal eixo ser o que direciona políticas de melhoria na educação, relaciona-se ao fato de que $52,38 \%$ dos psicólogos (mais da metade) atuam no Pronatec, programa voltado para essa demanda e para esse eixo.

Destaca-se que apenas 7,14\% dos 42 psicólogos entrevistados estão envolvidos em Políticas do eixo 2 (Políticas de formação e atuação do psicólogo escolar), sendo que, ao serem levantadas as limitações para a atuação dos psicólogos em suas respectivas instituições, quase $1 / 4$ das limitações $(22,45 \%)$ se relacionaram à formação falha no tocante à PEE e à falta de entendimento dos outros profissionais do coletivo escolar acerca da função desse profissional (limitações relacionadas a esse eixo).

\section{CONSIDERAÇÕES FINAIS}

Dessa forma, através da presente pesquisa foi possível fazer um mapeamento acerca da realidade do delineamento dos Psicólogos Escolares Educacionais nas Políticas Públicas de Educação do estado do Piauí, identificando, sobretudo, os eixos de políticas nos quais estão inseridos, assim como as demandas e limitações recorrentes na referida realidade.

Mais da metade tem sua atuação voltada para o eixo 3 de atuação em políticas públicas (Políticas de Melhoria na Educação), e quanto às demandas se sobressaem as questões de saúde mental e emocional, evasão escolar e infrequência e comportamento autolesivo.
Dentre as limitações, se destacam o déficit no suporte técnico/recursal, falta de mais profissionais na rede, assim como o desconhecimento por parte dos outros profissionais da real função do Psicólogo Escolar e Educacional. Quanto a essa última, foi percebida uma carência de ações no eixo de políticas relacionado, enquanto que se percebeu através dos relatos que as outras demandas mais recorrentes vêm sendo contempladas através do eixo 3 de políticas.

Espera-se que o levantamento aqui realizado possa ser utilizado a fim de delinear práticas futuras em Políticas Públicas Educacionais acerca das demandas levantadas, sobretudo com relação àquelas que são recorrentes, mas que, contudo, não vêm sendo contempladas nas práticas e nos modos de atuação.

Indica-se que mais estudos como esse sejam realizados em outros estados do Brasil, sobretudo nos estados do Nordeste brasileiro, ainda escasso de investigações desse perfil, para que assim possam ser feitos comparativos entre as realidades de atuação do Psicólogo Escolar Educacional nas Políticas Públicas Educacionais entre os estados brasileiros, a fim de compreender como se dá essa atuação de forma nacional.

Isso pode possibilitar uma ampliação da visão acerca dessa prática, contribuindo também para um maior reconhecimento e compreensão (do coletivo escolar, da sociedade e dos próprios profissionais da Psicologia) sobre o que é a Psicologia Escolar Educacional e sobre sua função não apenas psicoeducativa, mas também psicossocial.

\section{CONTRIBUIÇÃO DE CADA AUTOR}

Certificamos que todos os autores participaram suficientemente do trabalho para tornar pública sua responsabilidade pelo conteúdo. A contribuição de cada autor pode ser atribuída como se segue:

L. S. C. e F. N. contribuíram para a conceitualização e visualização do artigo; L. S. C. e B. S. C. conduziram a investigação; F. N. foi o supervisor, responsável pela obtenção de financiamento e metodologia; F. N. e L. S. C. fizeram a redação inicial do artigo (rascunho) e B. S. C. e F. N. são os responsáveis pela redação final (revisão e edição).

\section{AGRADECIMENTOS}

Os autores agradecem a CNPq por fomentar a pesquisa, aos integrantes dos núcleos de pesquisa PSIQUED e PSIPED pelo apoio na coleta de dados e aos órgãos e participantes da pesquisa pelos dados disponibilizados. 


\section{DECLARAÇÃO DE FINANCIAMENTO}

A pesquisa relatada no manuscrito não foi financiada por agências de fomento.

\section{DECLARAÇÃO DE CONFLITOS DE INTERESSE}

Os autores declaram que não há conflitos de interesse no manuscrito submetido.

\section{REFERÊNCIAS}

Antunes, M. A. M. (2003). Psicologia e educação no Brasil: um olhar históricocrítico. In: Meira, M. E. M.; Antunes, M. (Org.). Psicologia Escolar: teorias críticas (pp. 139-168). Casa do Psicólogo.

Barbosa, D. R., \& Souza, M. P. R. de. (2012). Psicologia Educacional ou Escolar? Eis a questão. Psicologia Escolar e Educacional, 16 (1), 163-173. https://doi.org/10.1590/ s1413-85572012000100018

Bardin, L. (2006). Análise de conteúdo. Edições 70. (Obra original publicada em 1977).

Barroco, S. M. S., \& Silva, R. I. M. (2015). Psicologia, ideologia e políticas públicas para educação: reflexões necessárias. In: Zibetti, M. L. T., Souza, M. P. R., \& Barroco, S. M. S. (Org.). Psicologia, políticas educacionais e escolarização (pp. 21-42). Pandion.

Brasil. Lei federal No 9394 de 20 de dezembro de 1996. Estabelece as diretrizes e bases da educação nacional. http:// www.planalto.gov.br/ccivil_03/leis/L9394.htm

Campos, H. R., Souza, M. P. R., \& Facci, M. G. D. (2018). Psicologia e políticas educacionais. Appris.

Checchia, A. K. A. (2015). Contribuições da Psicologia Escolar para a formação dos professores: um estudo sobre a disciplina Psicologia da Educação nas Licenciaturas [Tese de Doutorado, Universidade de São Paulo] Biblioteca Digital de Teses e Dissertações da USP. https://www.teses.usp. br/teses/disponiveis/47/47131/tde-07082015-114724/ pt-br.php

Checchia, A. K. A., \& Souza, M. P. R. de. (2018). A disciplina psicologia da educação na formação de professores: reflexões a partir da Psicologia Educacional e Escolar. In: Campos, H. R., Souza, M. P. R. de, \& Facci, M. G. D. (Org.). Psicologia e políticas educacionais (pp. 295-324). Appris.

Collares, C. A. L, \& Moysés, M. A. A. (2015). Preconceitos no cotidiano escolar: ensino medicalização ( $\left.2^{\mathrm{a}} \mathrm{ed}\right)$. Autor.

Cruz, L. R., \& Guareschi, N. (2017). Políticas públicas e assistência social: diálogo com práticas psicológicas. Editora Vozes Limitada.
Damasceno, M., \& Negreiros, F. (2018). Professores, fracasso e sucesso escolar: um estudo no contexto educacional brasileiro. Revista de Psicologia da IMED, 10 (1), 73-89. https://doi.org/10.18256/2175-5027.2018.v10i1.2572

Dimenstein, M. (2011). A ação clínica e os espaços institucionais das políticas públicas: desafios éticos e técnicos. In: Conselho Federal de Psicologia. V seminário nacional psicologia e políticas públicas: subjetividade, cidadania e políticas públicas: subjetividade, cidadania e políticas públicas (pp. 119-126). CFP. https://site.cfp.org.br/publicacao/v-seminrio-nacional-psicologia-e-polticas-pblicas-subjetividade-cidadania-e-polticas-pblicas/

Farah, M. F. S. (2016). Análise de políticas públicas no Brasil: de uma prática não nomeada à institucionalização do "campo de públicas". Revista Adm. Pública, 50 (6), 959-979. https://doi.org/10.1590/0034-7612150981

Fontes, V. (2010). O Brasil e o capital-imperialismo: Teoria e história. Editora UFRJ.

Gil, A. C. (2010). Como elaborar projetos de pesquisa. Atlas.

Gomes, A. M. M., \& Souza, M. P. R. (2015). O psicólogo escolar na educação: possibilidades e desafios de uma atuação na perspectiva crítica. In: Zibetti, M. L. T., Souza, M. P. R., \& Barroco, S. M. S. (Org.). Psicologia, políticas educacionais e escolarização (pp. 135-160). Pandion.

Harvey, D. (2011). O enigma do capital e as crises do capitalismo. Boitempo. (Obra original publicada em 2010)

Leonardo, N. S. T., Rossato, S. P. M., \& Constantino, E. P. (2018). Políticas públicas em educação e o fracasso escolar: as interlocuções com a psicologia. In: Campos, H. R., Souza, M. P. R., \& Facci, M. G. D. (Org.). Psicologia e políticas educacionais (pp. 43-66). Appris.

Macedo, J. P., \& Dimenstein, M. (2011). Formação do psicólogo para a saúde mental: a psicologia piauiense em análise. Interface: Comunicação, Saúde, Educação, 15(39), 1145-1158. https://doi.org/10.1590/s1414-32832 011005000021

Martinez, A. M. (2003b). O compromisso social da psicologia: desafios para a formação dos psicólogos. In: Bock, A. M. M. (Org.). Psicologia e compromisso social (pp. 143-160). Cortez.

Martinez, A. M. (2010). O que pode fazer o psicólogo na escola? Em Aberto, 23 (83), 39-56. https://doi.org/10.24109/21766673.emaberto.23i83

Meira, M. E. M. (2000). Psicologia Escolar: pensamento crítico e práticas profissionais. In: Tanamachi, E., Proença, M., \& Rocha, M. L. (Orgs.). Psicologia e Educação: desafios teórico-práticos (pp. 35-71). Casa do Psicólogo.

Minayo, M. C. S. (2004). O desafio do conhecimento: pesquisa qualitativa em saúde ( $8^{\circ}$ ed.). Abrasco. 


\section{W NTERAC̄̃OEM IT PSICOLOGIA}

Negreiros, F., Zibetti, M. L. T., \& Barroco, S. M. S. (2018). Pesquisas em Psicologia e políticas educacionais: desafios para o enfrentamento à exclusão. CRV/Edufpi.

Patto, M. H. S. (1984). Psicologia e ideologia: uma introdução crítica à Psicologia. Queiroz.

Patto, M. H. S. (2000). A produção do fracasso escolar: histórias de submissão e rebeldia. Casa do Psicólogo.

Silva, C. A., \& Yamamoto, O. H. (2013). As políticas sociais na formação graduada do psicólogo no Piauí. Psicologia, ciência e profissão, 33 (4), 824-839. https://doi.org/10.1590/ s1414-98932013000400005

Souza, M. P. R. de, \& Checchia, A. K. A. (2003). Queixa escolar e atuação profissional: apontamentos para a formação de psicólogos. In: Meira, M. E. M., \& Antunes, M. (Org.). Psicologia escolar: teorias críticas (pp. 105-137). Casa do Psicólogo.
Bruna Saraiva Candeira, Leilanir de Sousa Carvalho e Fauston Negreiros

Souza, M. R. P. de, \& Cunha, B. B. (2010). Projeto de lei e políticas públicas: o que a psicologia tem a propor para a educação? In: Conselho regional de psicologia de São Paulo, Grupo Interinstitucional Queixa Escolar (Org.). Medicalização de crianças e adolescentes: conflitos silenciados pela redução de questões sociais a doença de indivíduos (pp. 215-228). Casa do Psicólogo.

Urt, S. C. (2017). Políticas educacionais e formação: produção, projetos e ações em psicologia. Oeste.

Vygotsky, L. S. (1999b). Teoria e método em psicologia. Martins Fontes.

Zibetti, M. L. T., Pacífico, J. M., \& Tamboril, M. I. B. (2018). A educação como direito: considerações sobre políticas educacionais. In: Campos, H. R., Souza, M. P. R., \& Facci, M. G. D. (org.). Psicologia e políticas educacionais (pp. 17-42). Curitiba: Appris.

Submetido em: $21 / 06 / 19$ $1^{\text {a }}$ decisão editorial em: 07/05/20 Aprovação em: 13/05/20 